\title{
INTOXICAÇÃO AGUDA POR ORGANOFOSFORADO EM BOVINOS DO PARANÁ, BRASIL
}

(Acute poisoning by organophosphate in bovine cattle of Parana state, Brazil)

Emerson Sebastião Bertoni ${ }^{1}$, Alexander Welker Biondo ${ }^{2}$, Carolina Dutra Minozzo², Juliana Sperotto Brum², Ivan Roque Barros Filho², João Henrique Perotta ${ }^{3}$

\footnotetext{
${ }^{1}$ Agência de Defesa Agropecuária do Paraná, Paraná, Brasil.

${ }^{2}$ Programa de Pós-graduação em Ciências Veterinárias, Universidade Federal do Paraná, Curitiba, Paraná, Brasil.

${ }^{3}$ Departamento de Medicina Veterinária, Universidade Federal do Paraná, Curitiba, Paraná, Brasil.
}

*Correspondência: perotta@ufpr.br

RESUMO: Relata-se a intoxicação aguda por organofosforado em bovinos mestiços zebuínos, criados no Paraná. Dos sessenta animais pulverizados com solução de diazinon, com concentração aproximada superior a cinco vezes a dose recomendada para controle de ectoparasitas, 51 morreram no intervalo de 24 horas. Os sinais clínicos mais evidentes foram tremores musculares, sialorreia, timpanismo, miose, prostração, decúbito, culminando com o óbito. Esse tipo de acidente ainda ocorre no Brasil em decorrência do insuficiente treinamento do pessoal que manipula esses produtos e a possibilidade de os adquirirem sem receituário médico veterinário.

Palavras-chave: diazinon; mortalidade; acidente; envenenamento

ABSTRACT: An acute organophosphate poisoning in bovine Zebu-mixed breed cattle, raised in Parana state, Brazil has been reported. Out of sixty animals sprayed with diazinon solution, with approximated concentration over 5 -fold the recommended dose for ectoparasite control, 51 died within 24-hour interval. The most evident clinical signs were muscle tremors, sialorrhea, bloat, miosis, prostration, decubitus, leading to death. This type of accident may still occur in Brazil as consequence of insufficient training of personal who handle such products and the possibility of purchase them without veterinarian prescription.

Key Words: diazinon; mortality; intoxication; poisoning

\section{INTRODUÇÃO}

Os organofosforados são
compostos $\begin{gathered}\text { utilizados } \\ \text { como }\end{gathered}$
antiparasitários nos animais e como
inseticidas nas lavouras. Intoxicações
acidentais ocorrem durante a aplicações
de inseticidas em plantações, ou no uso
como antiparasitários em concentrações
inapropriadas (Barros e Driemeier,
2007). Além de ser potencialmente
nocivo para os animais o parasiticida tem
importante papel deletério também na

saúde de seres humanos (Oliveira e Burioli, 2009). São inibidores das colinesterases e absorvidos pela pele, por ingestão ou por inalação. Sua ação se dá pela inibição de enzimas colinesterases, especialmente a acetilcolinesterase, levando a um acúmulo de acetilcolina nas sinapses nervosas, desencadeando uma série de efeitos parassimpaticomiméticos. Este grupo de agrotóxicos, inseticidas, é responsável pelo maior número de intoxicações e mortes de pessoas no 
Brasil (Organização Pan-americana da Saúde - Organização Mundial da Saúde, 1996).

Os organofosforados mais frequentemente utilizados são diazinon, metaminofós, dimixion, fenitrotion, fention, fosfomet, triclorfon, clorfenrifós, ethione e clorpirifós (Grecco, et al. 2009). Existem relatos de intoxicação por organofosforados em bovinos (Barbosa et al. 2005; Borges 2007; Dalto et al. 2007; Oliveira Filho et al. 2009; Santos et al. 2014); bubalinos (Grecco et al. 2009), ovinos (Rissi et al. 2010), caprinos (Lopes et al. 2014), cão (Medeiros et.al, 2009); gato (Rodrigues, 2016) e em pessoas (Stroparo e Braguini, 2011).

Nas intoxicações de bovinos podem ser notados hiperexcitabilidade, balançar de cabeça, liquido espumoso eliminado pelas narinas, miose, nistagmo, tremor muscular e decúbito (Barbosa et al. 2005; Radostits et al. 2002). A avaliação da colinesterase presente no sangue e tecidos pode ser útil para o diagnóstico, embora, oscile de acordo com o tempo e quantidade do produto ingerido (Barbosa et al. 2005).

Neste trabalho foi descrito a mortalidade de bovinos por intoxicação aguda pelo organofosforado diazinon em pequena propriedade rural no estado do Paraná, Brasil.

\section{MATERIAL E MÉTODOS}

Relata-se a morte de 51 bovinos em propriedade rural de Iporã - Paraná. Os dados clínicos e epidemiológicos foram obtidos junto ao proprietário e médico veterinário da Agência de Defesa Agropecuária do Paraná. Na propriedade eram criados 134 bovinos, mestiços zebuínos, machos e fêmeas. O proprietário aplicou por via cutânea na forma de aspersão, um produto a base de diazinon, organofosforado para controle de ectoparasitas. Para tanto, diluiu o conteúdo de $100 \mathrm{~mL}$ em 20 litros de água para borrifar a solução com auxílio de bomba costal. A diluição recomendada pela bula do produto era de $20 \mathrm{~mL}$ para cada 20 litros de água.

A pulverização foi feira em 60 bovinos por volta das 17 horas do dia sete de fevereiro de 2017, em ensolarada e quente tarde de verão. Os sinais clínicos e mortes começaram a ocorrer após 20 minutos da aspersão. Houve tratamento de alguns animais com atropina e somente nove sobreviveram. Não houve necropsia e os cadáveres foram enterrados em vala profunda.

\section{RESULTADOS E DISCUSSÃO}

Os animais apresentaram, de maneira geral: tremores musculares, sialorreia, timpanismo, miose, diarreia, prostração, decúbito. No período de 24 horas morreram 51 animais, sendo 14 machos com idade entre 10 e 12 meses, um macho e 34 fêmeas com 13 a 24 meses e um macho uma fêmea com mais de 25 meses (figura 1).

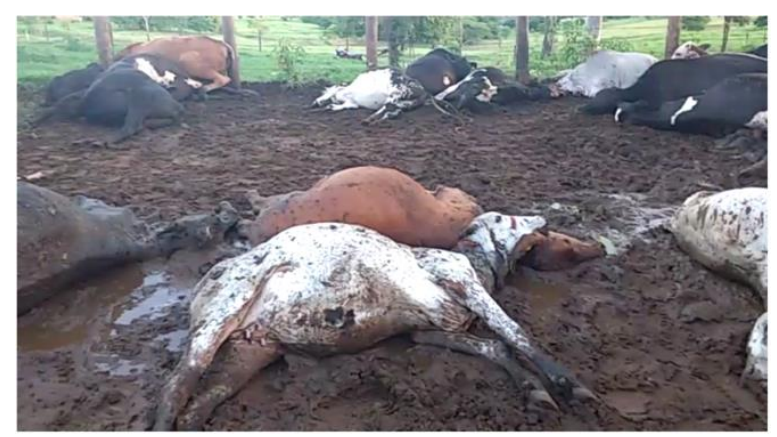

Figura 1 - Bovinos zebuínos mortos após aspersão com diazinon para controle de ectoparasitas.

As intoxicações

por organofosforados possuem importância na clínica veterinária, pois são vários os relatos de intoxicação e mortalidade. Em pequena propriedade do Distrito Federal 23 bovinos mestiços adultos e um bezerro foram banhados com solução de produto a base de diazinon em concentração 5 a 6 vezes maior que a recomendada (Castro et al. 2007). No presente relato, a dose do produto 
aplicado por aspersão cutânea foi estimada, coincidentemente, em cinco vezes maior que a preconizada, resultando em grave intoxicação. O uso de aspersão de uma solução de diazinon a $0,05 \%$ tem sido bem tolerada em bezerros, mas uma solução a $0,1 \%$ causa intoxicação. Bovinos adultos toleram a aspersão de uma solução a $0,1 \%$ repetida em intervalos semanais (Black, 1998).

Altas concentrações do produto, erros na posologia, altas temperaturas ambientais, acidentes e facilidade na aquisição e uso do produto, sem receituário médico veterinário, são fatores predisponentes e determinantes para os acidentes. A aspersão nos 60 bovinos, além de diluição menor que a recomendada, aconteceu em dia com temperatura ambiental elevada, que poderia ter facilitado a absorção do diazinon pela pele. No Rio Grande do Sul, em nove surtos, morreram 151 $(45,8 \%)$ bovinos de 330 intoxicados por diazinon por uso inadequado, com concentrações que variavam de 2 a 151 vezes maiores que as recomendadas (Santos et al. 2014). Ainda no Rio Grande do Sul, 26 vacas e novilhas adoeceram e 20 morreram num rebanho de 49 animais. Elas haviam ingerido água contaminada, que havia sido utilizada para limpeza de equipamentos agrícolas contendo agrotóxicos em propriedade vizinha (Oliveira filho et al. 2010). No Pará um produto a base de $60 \%$ de organofosforado (DDVP) e $5 \%$ de cipermetrina diluído com óleo vegetal comestível na proporção de 1:2, aplicando-se $20 \mathrm{ml}$ dessa mistura por bovino na região dorso-lombar (pour on). Os sinais clínicos se manifestaram e houve mortalidade (Barbosa et al. 2005).

Os sinais clínicos dos animais deste relato, foram semelhantes aqueles descritos por outros autores: tremores musculares, timpanismo, sialorreia, miose, decúbito esternal, posição de auto auscultação, pescoço em S e morte (Radostits, et al. 2002; Barbosa et al. 2005; Santos et al, 2014). Um surto de intoxicação aconteceu em bezerras de 15 dias de idade criadas propriedade leiteira situada no Uruguai. O produto usado pour on foi o ethion $15 \%$ e sete animais de vinte animais, apresentaram sinais clínicos de incoordenação, sialorreia, lacrimejamento, prostração, protrusão da língua, miose e fraqueza muscular. Houve sucesso com o tratamento à base se sulfato de atropina $1 \%(0,50 \mathrm{mg} / \mathrm{Kg})$ e cloreto de sódio $0,9 \%$ por via intravenosa (Dalto et.al.2007). O tratamento para bovinos com atropina deve ser feito na dose de $0,25 \mathrm{mg} / \mathrm{Kg}$. Em animais gravemente afetados, um terço da dose deve ser administrada lentamente por via intravenosa diluída $(2 \%)$ e o restante por via intramuscular. Deve haver nova aplicação após quatro a cinco horas, se os sinais clínicos persistirem (Radostits et al. 2002). O tratamento com atropina, no presente estudo, foi feito de forma não técnica pelo proprietário dos animais. Desse modo não se pode afirmar que a terapia foi ineficiente, sob o ponto de vista da potencial eficácia da atropina na reversão da intoxicação ou, ainda, se os sobreviventes foram beneficiados por ela. O tratamento foi feito tardiamente e não se tem certeza do cálculo da dose terapêutica e intervalos de aplicação. Castro e colaboradores (2007) em descrição da mortalidade de bovinos por intoxicação por diazinon, mencionaram a alta temperatura ambiental, a necessidade dos animais terem caminhado aproximadamente $1,5 \mathrm{~km}$, piorando a situação clínica e a ineficiência do tratamento com atropina.

Existem relatos de intoxicação por organofosforados em outras espécies de ruminantes em situações semelhantes a este relato. No Rio Grande do Sul houve 61 mortes de búfalos $(22,8 \%$ dos animais) com sinais clínicos e óbito que 
se iniciaram após 7 dias da aplicação pour on de clorpirifós [0,0-dietil 0-(3,5,6tricloro-2-piridil)-fósforo-tionato] na dose de $10 \mathrm{ml} / 100 \mathrm{~kg}$ de peso animal $(12 \mathrm{mg} / \mathrm{kg}$ ) para combate a infestação por piolhos (Grecco, et. al., 2009). Um surto de intoxicação foi descrito em oito de vinte cabras adultas não gestantes, que receberam triclorfon na dose de $100 \mathrm{mg} / \mathrm{Kg}$ para o tratamento de infestação por nematoides gastrointestinais. Com 0 desenvolvimento dos sinais clínicos foram medicadas com sulfato de atropina e, no entanto, duas morreram. Curioso nesse relato foi que 53 ovinos receberam o mesmo tratamento com triclorfon e não apresentaram nenhum sinal clínico relacionado a intoxicação. Os autores sugerem uma possível sensibilidade aumentada ao triclorfon pelas cabras (Lopes et al. 2014). Por estes relatos, pode-se supor que as ocorrências destas intoxicações acontecem em um número muito maior de animais e pessoas, devido à falta de informação e negligencia no uso de produtos organofosforados.

\section{CONCLUSÃO}

A intoxicação por produtos organofosforados ainda acontece no Brasil e tem causado prejuízos importantes. Em decorrência do preparo insuficiente das pessoas que os utilizam e pela possibilidade de compra dos produtos sem receituário e orientação médico veterinária, o risco da ocorrência de acidentes aumenta consideravelmente.

\section{REFERENCIAS}

BARBOSA, J.D.; OLIVEIRA, C.M.C.; DUARTE, M.D.; ALBERNAZ, T.T. Intoxicações com Manifestações Neurológicas em Ruminantes. Simpósio Mineiro de Buiatria II, Belo Horizonte, MG, Brasil, 2005.
BARROS, C.S.L.; DRIEMEIER, D. Intoxicação por organofosforados e carbamatos. In RIET-CORREA, F.; SCHILD, A.L.; LEMOS, R.A.A.; BORGES, J.R.J. Doenças dos ruminantes e equídeos. $3^{\mathrm{a} e d .} \mathrm{Ed}$. Pallotti, Santa Maria, v.2. p.80-85, 2007.

BLACK, W.D. Insecticide and acaricide (organic) toxicity. In. AIELLO, S.E. The merck veterinary manual. $8^{\text {th }}$ ed. Merk \& Co, INC, Whitehouse Station, N.J., p.2061-2071, 1998.

CASTRO, M.B.; MOSCARDINI, A.R.C.; REIS JR, J.L.; NOVAES, E.P.F; BORGES, J.R.J. Intoxicação aguda por diazinon em bovinos. Ciência Rural, v.37, n.5, p.1498-1501, 2007.

DALTO, C.; ALBORNOZ, L.; GONZALEZ, P.C.S.; BITENCOURT, A.P.G.; GOMES, D.C.; PEDROSO, P.M.O.; BANDARRA, P.M. Organophosphate poisoning in calves in Uruguay (Case Report). Acta Scientiae Veterinariae, v.39, n.3, p.983, 2011.

GRECCO, F.B.; SCHILD, A.L.; SOARES, M.P.; RAFFI, M.B.; SALLIS, S.V.; DAMÉ, M.C. Intoxicação por organofosforados em búfalos (Bubalus bubalis) no Rio Grande do Sul. Pesquisa Veterinária Brasileira, v.29, n.3. p.211-214, 2009.

LOPES, W.D.Z.; CARVALHO, R.S.; GRACIOLI, D.P.; OLIVEIRA, P.V.; PEREIRA, V. MARTINEZ, A.C.; MAZZUCATTO, B.C. Intoxicação aguda por triclorfon em caprinos tratados com a dose terapêutica. Pesquisa Veterinária Brasileira, v.34, n.2, p.114-118, 2014.

MEDEIROS, R.J.; MONTEIRO, F.O.; SILVA, G.C.; NASCIMENTO JUNIOR, A. Casos de intoxicações exógenas em cães e gatos atendidos na Faculdade de Veterinária da Universidade Federal Fluminense durante o período de 2002 a 2008. Ciência Rural, v.39, n.7, p.21052110, 2009. 
OLIVEIRA, M.L.F., BURIOLA, A.A. Gravidade das intoxicações por inseticidas inibidores das colinesterases no noroeste do estado do Paraná, Brasil. Revista Gaúcha Enfermagem, 2009, v.30, n.4, p.648-55.

OLIVEIRA FILHO, J.C.; CARMO, P.M.S.; PIEREZAN, F.; TOCHETTO, C.; LUCENA, R.B.; RISSI, D.R.; BARROS, C.S.L. Intoxicação por organofosforado em bovinos no Rio Grande do Sul. Pesquisa Veterinária Brasileira, v.30, n.10, p.803-806, 2010.

ORGANIZAÇÃO PAN-AMERICANA DA SAÚDE - ORGANIZAÇÃO MUNDIAL DA SAÚDE. Manual de vigilância da saúde de populações expostas a agrotóxicos, Brasília, 69p, 1996.

RADOSTITS, M.O.; GAY, C.C.; BLOOD, D.C.; HINCHCLIFF, K.W. Clínica Veterinária, 9aed, Guanabara Koogan, Rio de Janeiro, 2002, 1737p.

RISSI, D.R.; PIEREZAN, F.; OLIVEIRA FILHO, J.C.; FIGHERA, R.A.; IRIGOYEN, L.F.; KOMMERS, G.D.; BARROS, C.S.L. Doenças de ovinos da região Central do Rio Grande do Sul: 361 casos. Pesquisa Veterinária Brasileira, v.30, n.1, p.21-28, 2010.

RODRIGUES, E.; REFOSCO, B.K.; MORESCO, B.N.; CAON, E.; BIRK, J.L.; FREITAS, G.C. Intoxicação acidental por organofosforado em gato doméstico (Felis catus) - relato de caso. Seminário de Pesquisa Ensino e Extensão da Universidade Federal da Fronteira Sul Anais, 2016.
SANTOS,
B.L.;
PEREIRA- MARCOLONGO, C.; STIGGER, A.L.; COELHO, A.C.; SOARES, M.P.; SALLIS, E.S.V.; BARRETO, F.; SCHILD, A.L. Uso inadequado de organofosforados: uma prática de risco para bovinos no Sul do Rio Grande do Sul. Pesquisa

Veterinária Brasileira, v.34, n.7, p.655658, 2014.

STROPARO, L.F; BRAGUINI, W.L. Avaliação da exposição à organofosforados entre produtores de tabaco de uma localidade do município de Irati - Paraná. Publicatio UEPG, v.17, n.1, v. 39-50, 2011. 